\title{
Clinical feasibility of sphincter-preserving resection with transanal rectal dissection for low-lying rectal cancer in Japanese patients: a single-center cohort study
}

\author{
Kimihiko Funahashi', Junichi Koike, Hiroyuki Shiokawa1, Mitsunori Ushigome1, Tomoaki Kaneko', \\ Satoru Kagami ${ }^{1}$, Takamaru Koda ${ }^{1}$, Tatsuo Teramoto ${ }^{2}$ \\ 'Department of General and Gastroenterological Surgery, Toho University Omori Medical Center, Tokyo 143-8541, Japan. \\ 2Department of Surgery, Jyujyo Hospital, Chiba 292-0003, Japan.
}

Correspondence to: Dr. Kimihiko Funahashi, Department of General and Gastroenterological Surgery, Toho University Omori Medical Center, 6-11-1 Omorinishi, Ota-ku, Tokyo 143-8541, Japan. E-mail: kingkong@med.toho-u.ac.jp

How to cite this article: Funahashi K, Koike J, Shiokawa H, Ushigome M, Kaneko T, Kagami S, Koda T, Teramoto T. Clinical feasibility of sphincter-preserving resection with transanal rectal dissection for low-lying rectal cancer in Japanese patients: a single-center cohort study. Mini-invasive Surg 2018;2:27. http://dx.doi.org/10.20517/2574-1225.2018.28

Received: 27 May 2018 First Decision: 1 Aug 2018 Revised: 2 Aug 2018 Accepted: 2 Aug 2018 Published: 28 Aug 2018

Science Editor: Gordon N. Buchanan Copy Editor: Jun-Yao Li Production Editor: Huan-Liang Wu

\begin{abstract}
Aim: Recently, the transanal down-to-up rectal dissection, a new approach to improve the difficult total mesorectal excision (TME) for low-lying rectal cancer, has been popularized. This study assessed the long-term oncologic and functional outcomes after sphincter-preserving resection combined with transanal rectal dissection (TARD) under direct vision for both complete TME and preservation of the internal anal sphincter (IAS) as much as possible to clarify the clinical feasibility of this approach.
\end{abstract}

Methods: A prospective cohort study was conducted in 90 Japanese patients between April 2003 and March 2012.

Results: Abdominoperineal resection (APR) was needed in 17 patients (18.9\%) including 14 salvage APRs. Local recurrences occurred in 5 sphincter-preserving resection patients (6.8\%). No significant between-group differences were observed in overall survival or 5-year disease-free survival. A significant benefit of preserving the internal anal sphincter completely in sphincter-preserving resection was found on the Wexner incontinence score $(P=0.005)$, low anterior resection syndrome score $(P=0.002)$, and visual analogue scale $(P=0.047)$.

Conclusion: TARD, performed under direct vision for both complete TME and preservation of the IAS as much as possible in sphincter-preserving resections for low-lying rectal cancers in Japanese patients, does not negatively impact oncologic outcomes and could have the benefit of minimizing postoperative anorectal dysfunction by preserving the internal anal sphincter.

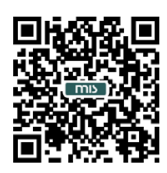


Keywords: Transanal rectal dissection, transanal total mesorectal excision, intersphincteric resection, sphincterpreserving resection, anorectal function outcomes, oncologic outcomes

\section{INTRODUCTION}

In surgery for rectal cancer, total mesorectal excision $(\mathrm{TME})^{[1,2]}$ and negative circumferential resection margins ${ }^{[3,4]}$ are prerequisites for minimizing local tumor recurrence after surgery for rectal cancer. However, male sex, high body mass index, visceral obesity, a narrow pelvis, bulky tumor and an advanced T-stage pose technical challenges during surgery due to poor visualization of the mesorectal planes, especially with laparoscopic surgery ${ }^{[5,6]}$. Actually, the ALaCart ${ }^{[7]}$ and ACOSOG Z6051 ${ }^{[8]}$ randomized controlled trials failed to show the noninferiority of laparoscopic surgery compared with open surgery for oncologic outcomes. Additionally, minimizing postoperative anorectal dysfunction has been a major matter in sphincter preservation for low-lying rectal cancer (LRC) near the anus. Intersphincteric resection (ISR) makes sphincter preservation possible for many patients with $\mathrm{LRC}^{[9]}$. Laparoscopic ISR has been shown to be more feasible and beneficial than open ISR ${ }^{[10]}$. Recently, a new approach, the transanal total mesorectal excision (TaTME), has attracted increasing attention as a promising technique for rectal cancer patients who may be poor candidates for total TME. A transanal approach has another benefit: the level of the distal resection margin is determined as the first step in the anal canal, taking care to preserve the internal anal sphincter (IAS) as much as possible for LRC near the anus.

More recently, TaTME has been shown to be feasible in a randomized trial in France ${ }^{[11]}$, a case-matched study ${ }^{[12]}$ and a meta-analysis ${ }^{[13]}$. However, its feasibility for those of Asian race, including Japanese patients, remains unclear. As the average body mass index in Japan increases each year ${ }^{[14,15]}$, the transanal approach may represent a solution for obese Japanese patients with a narrow pelvis and a bulky mesorectum.

The aim of this study was to clarify the clinical feasibility of this new technique by analyzing the long-term oncologic and functional outcomes after sphincter-preserving resection (SPR) combined with transanal rectal dissection (TARD) under direct vision for both complete TME and preservation of the IAS as much as possible $e^{[16]}$.

\section{METHODS}

\section{Patients}

The study was approved by the ethics committee of Toho University Omori Medical Center (No. 17-41). Informed consent was obtained from all patients in this study. All patients who underwent laparoscopic and open SPR combined with TARD for LRC from April 2003 to March 2012 were included in this prospective observational cohort study. We evaluated 90 patients undergoing laparoscopic and open SPR at our institution for the feasibility of TARD for LRC. The inclusion criterion was LRC located $\leq 5 \mathrm{~cm}$ from the anal verge. Patients of both sexes and various ages were included. The exclusion criteria for TARD included lesions classified as T4b or N2-3, lateral lymph-node involvement, and the presence of distant metastases. An immediate conversion to an abdominoperineal resection (APR) was performed if we observed any tumor invasion into the external anal sphincter or the levator ani muscle during the dissection of the internal anal sphincter and external anal sphincter muscles.

\section{Surgical technique}

The surgical technique for transanal retrograde dissection of the low rectum has been described previously ${ }^{[13]}$ [Figure 1]. Briefly, the anal canal was exposed using a self-retaining retractor (Lone Star Retractor; Lone Star Medical Products Inc., Houston, TX). The distal aspect of the canal at the lower margin of the tumor was closed using purse-string sutures under direct visualization, and the anal canal was irrigated 

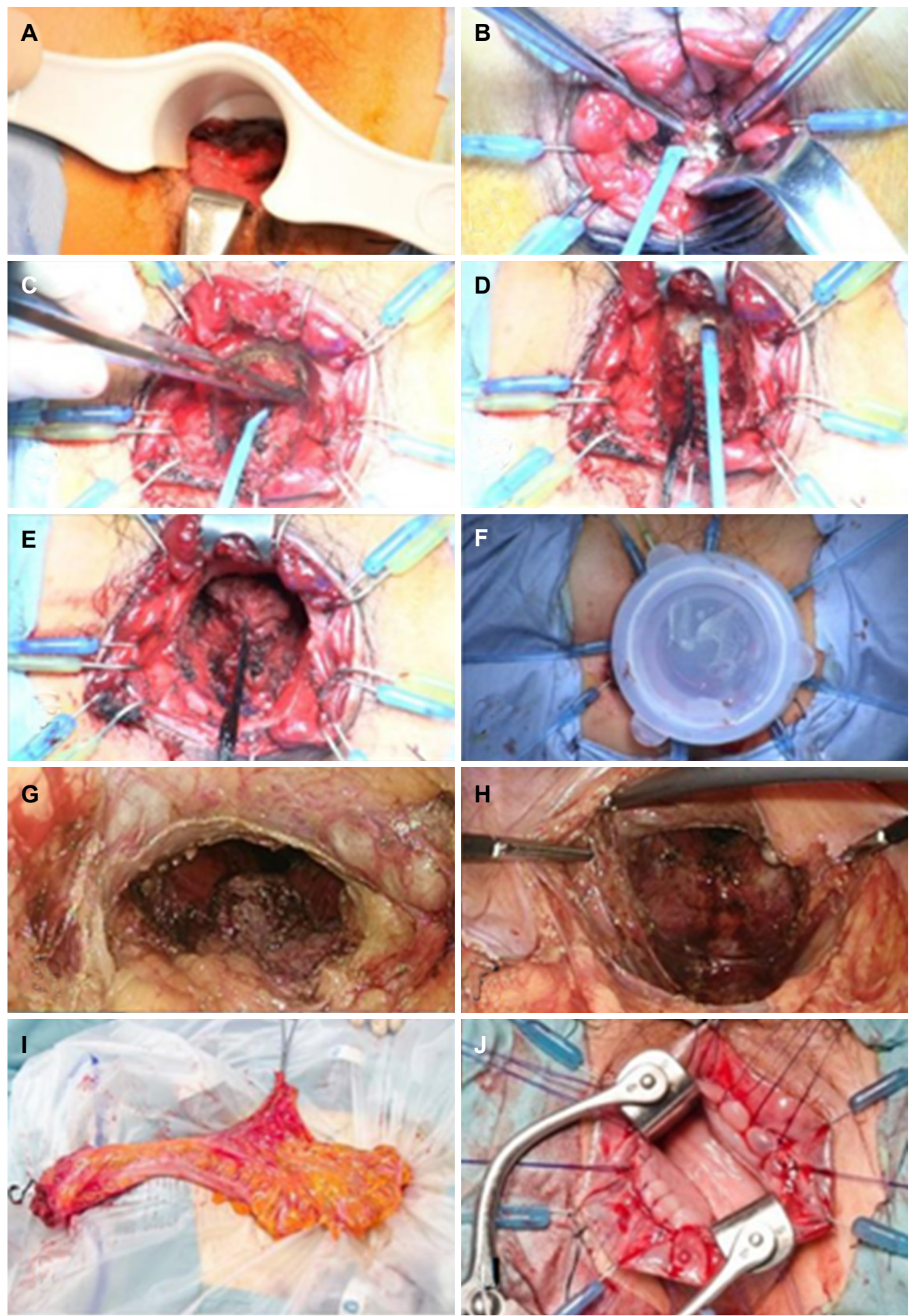

Figure 1. Photographs showing the procedure of an intersphincteric resection combined with transanal rectal dissection. A: Tumor was found at $4 \mathrm{~cm}$ from the anal verge, on the posterior side of the rectum; B-D: division of the rectum on the posterior side was performed, taking care to preserve the internal anal sphincter as much as possible. The rectum was circularly incised, closing the cut end with an interrupted suture, and the rectum (including the tumor) was mobilized proximally, exposing the levator ani muscle; E: the rectum, including the mesorectum, was divided and mobilized up to the peritoneal reflection on the anterior side and to the rectosacral ligament on the posterior side; F: a Lap Disc Mini (Hakko Co., Ltd, Chikuma-shi, Japan) was adapted to the anal canal to maintain pressure during laparoscopy; G-H: the rectum, including the entire mesorectum, was completely removed from the pelvic floor. To avoid nerve injury in this patient, Denonvilliers' fascia was not dissected; I: the colon and rectum were extruded through the umbilical wound and resected; J: a coloanal anastomosis was hand-sutured transanally 
with $5 \%$ povidone-iodine solution. Division of the rectum on the posterior side was then performed, taking care to preserve the IAS as much as possible. The rectum was circularly incised, closing the cut end with an interrupted suture, and the rectum (including the tumor) was mobilized proximally, exposing the levator ani muscle. If the surgeon suspected tumor invasion into the dissected plane, the procedure was immediately converted to an APR. The rectum, including the mesorectum, was divided and mobilized up to the peritoneal reflection on the anterior side and to the rectosacral ligament on the posterior side. The 10 o'clock and 2 o'clock positions around the prostate were dissected on the abdominal part of the organ in order to avoid excessive dissection around these positions that could cause nerve injury and result in sexual dysfunction ${ }^{[17]}$.

In the abdominal portion of a laparoscopic SPR, a Lap Disc Mini (Hakko Co., Ltd, Chikuma-shi, Japan) was adapted to the anal canal to maintain pressure during laparoscopy. A camera port was inserted into the umbilicus via a trocar; moreover, an operative port was inserted into the mid-lower abdominal region, and 2 additional operative ports were inserted into the left and right McBurney's points. During routine intra-abdominal exploration, gauze was placed on the dissected plane as a landmark that could be identified, through the peritoneum, from the anterior side of the rectum. The sigmoid and descending colon were completely mobilized from the subretroperitoneal fascia to ensure that the subsequent coloanal anastomosis was free of tension. The sigmoid colon and its mesentery were then removed, and the lymph nodes around the inferior mesenteric artery were dissected using a harmonic scalpel; additionally, the inferior mesenteric artery was ligated at a high level using an endoclip. Denonvillier's fascia was dissected, exposing, on the anterior side, the seminal vesicles and prostate gland in male patients and the posterior wall of the vagina in female patients. The lower rectum and mesorectum were mobilized from the sacrum, through the anus, on the divided plane between the visceral and parietal endopelvic fascia. The lateral ligaments of the rectum and the neurovascular bundle were gradually divided, using a harmonic scalpel, from the inner limit of the inferior hypogastric nerve fibers. The rectum, including the entire mesorectum, was completely removed from the pelvic floor. The colon and rectum were extruded through the umbilical wound and resected. A coloanal anastomosis was sutured transanally. Reconstruction was performed with a J-pouch or coloplasty, if possible. Finally, a diverting ileostomy was created; this was reversed 6 months after surgery. Although most parts of the procedure during the abdominal portion were performed by the surgical staff of the division of colorectal surgery, the anal portion of the surgery was performed only by the senior author (KF).

\section{Definition of ISR}

The ISR procedure partially or totally resects the IAS by dissecting the intersphincteric space. In this study, we defined partial ISR as a one-third resection of the upper part of the IAS between the dentate line and the intersphincteric groove, and we defined a massive ISR as a more than two-thirds resection between the dentate line and the intersphincteric groove. We take care to preserve the IAS as much as possible during division of the rectum. Rectal dissection beyond the dentate line with coloanal anastomosis was defined as a conventional coloanal anastomosis (conventional CAA).

\section{Functional assessment}

Anorectal function following ISR or conventional CAA was measured using structured questionnaires at regular intervals following closure of the diverting stoma. Patients answered questions on daily stool frequency and the presence of fecal urgency (incapacity to restrain defecation for more than $5 \mathrm{~min}$ ). We also used the Wexner incontinence (WI) score ${ }^{[16]}$, the low anterior resection syndrome (LARS) score ${ }^{[18]}$, and a survey assessing the patients' satisfaction with their daily bowel-movement habits that employed a visual analogue scale (VAS). Complete incontinence was defined as a WI score of 20. In this study, the ISR patients were divided into 2 groups: partial ISR and massive ISR.

\section{Postoperative follow-up}

After surgery, patients were followed in the clinic every 3 months to be monitored for cancer recurrence 
and anorectal function. Blood tests at each visit included carcinoembryonic antigen and carbohydrate antigen 19-9 (CA19-9) levels. Patients were evaluated every 3 months using computed tomography or abdominal ultrasonography for the first 3 years and every 6 months thereafter. Local recurrence was defined as any recurrence that was diagnosed or suspected in the pelvis, either alone or with other metastases.

Function was assessed using a questionnaire that included questions on stool frequency and fecal urgency. We used the WI score and assessed patient satisfaction using the VAS score previously described. This questionnaire was administered by the medical staff to all patients who underwent SPR at all clinical follow-up appointments. We evaluated the effects of the degree of IAS resection on the patients' long-term anorectal function.

\section{Statistical analysis}

Data were analyzed using either the chi-squared test or Fisher's exact test. Continuous variables were compared using the Kruskal Wallis H-test. Survival rates were assessed using Kaplan-Meier curves and the logrank test. A $P$-value of $<0.05$ was considered statistically significant. Statistical analyses were performed using Predictive Analytics SoftWare (PASW), version 18 (SPSS, Inc., Chicago, IL).

\section{RESULTS}

\section{Patient characteristics}

Ninety patients (63 male, 27 female) with a median age of 62 years (range 33-80 years) were enrolled. The median BMI was $22.5 \mathrm{~kg} / \mathrm{m}^{2}$ (range $16.7-32.9 \mathrm{~kg} / \mathrm{m}^{2}$ ). Fifteen patients $(16.7 \%$ ) had received preoperative chemoradiation therapy (pre-CRT). In this series, all tumors were designated as type II-III, according to Rullier's classification ${ }^{[19]}$. Seventeen patients (18.9\%) required intraoperative conversion to APR: in 14 patients, this was because of the surgeon's suspicion for direct tumor invasion into the levator ani muscle, prostate, or vagina; in 2 patients, there was ischemia of the descending colon; and in 1 patient, anatomic disorientation occurred. In the 73 patients who underwent successful SPR, efforts were made to preserve the IAS as much as possible to avoid postoperative anorectal dysfunction. In 21 of these 73 patients (28.8\%), the IAS was completely preserved, and the coloanal anastomosis was hand sewn; 33 patients underwent partial ISR, and 19 underwent massive ISR. According to Quirke's classification, the weighted mean of the quality of the mesorectum dissection was complete TME in $94.5 \%$ and nearly complete TME in $1.4 \%$. Also, the rate of involvement of the circumferential resection margin was $2.7 \%$.

The pathologic tumor-node-metastasis (pTNM) staging in the patients who underwent SPR was stage I in 27 patients (37.0\%), stage II in 23 patients (31.5\%), and stage III in 22 patients (30.1\%). The pTNM staging of the patients who underwent APR was stage I in 3 patients (17.6\%), stage II in 9 patients (52.9\%), and stage III in 4 patients $(23.5 \%)$. Because of a complete response to pre-CRT, pTNM staging could not be performed in 2 patients ( 1 in each group). Although in stage II and III advanced disease was observed more frequently in the patients who underwent APR, there was no statistically significant difference between the APR and SPR groups [Table 1].

\section{Oncologic results}

During a median follow-up period of 3958 days (range 2778-6583 days), recurrence developed in 13 of the SPR patients (17.8\%) and in 5 of the APR patients (29.1\%). Distant recurrence developed more frequently in the APR patients, while local recurrence occurred exclusively in those patients who underwent SPR [Table 2]. Local recurrences developed around the internal iliac artery in 4 patients and around the prostate in 1 patient. One patient with a local recurrence underwent pre-CRT because of locally advanced cancer (cT4N2Mo), and the remaining 4 patients were diagnosed with clinical stage III disease [Table 3].

The 5-year overall survival rates were $88.1 \%$ and $87.5 \%$ in the SPR and APR groups, respectively. The 5-year disease-free survival rates were $85.0 \%$ and $80.8 \%$ in the SPR and APR groups, respectively. No significant 
Table 1. Patient characteristics of the APR and SPR groups

\begin{tabular}{|c|c|c|c|}
\hline & SPR $(n=73)$ & APR $(n=17)$ & $P$ value \\
\hline Gender (\%) & & & 0.256 \\
\hline Male & $49(67.1)$ & $14(82.4)$ & \\
\hline Female & $24(32.9)$ & $3(17.6)$ & \\
\hline Age, years (range) & $61(33-79)$ & $69(40-80)$ & 0.013 \\
\hline $\mathrm{BMI}, \mathrm{kg} / \mathrm{m}^{2}$ (range) & $23.3(16.7-32.9)$ & $21.6(17.5-32.8)$ & 0.160 \\
\hline Pre-CRT (\%) & $14(19.2)$ & $1(5.9)$ & 0.286 \\
\hline Operation type & & & 0.040 \\
\hline Open & $33(45.2)$ & $13(76.5)$ & \\
\hline Laparoscopic & $40(54.8)$ & $4(23.5)$ & \\
\hline Quality of TME (\%) & & & 1.000 \\
\hline Complete & $69(94.5)$ & $17(100)$ & \\
\hline Near complete & $1(1.4)$ & 0 & \\
\hline NE & 3 & 0 & \\
\hline Circumferential resection margin (\%) & & & 1.000 \\
\hline Negative & $68(93.1)$ & $17(100)$ & \\
\hline Positive & $2(2.7)$ & 0 & \\
\hline $\mathrm{NE}$ & 3 & 0 & \\
\hline Maximum tumor size in specimen, $\mathrm{mm}$ (range) & $34.5(8-109)$ & & \\
\hline Pathological TNM staging & & & 0.243 \\
\hline । & $27(37.0)$ & $3(17.6)$ & \\
\hline$\|$ & $23(31.5)$ & $9(52.9)$ & \\
\hline III & $22(30.1)$ & $4(23.5)$ & \\
\hline NE & $1(1.4)$ & $1(6.0)$ & \\
\hline
\end{tabular}

Data shown as median (range) or $n$ (\%). BMI: body mass index; Pre-CRT: preoperative chemoradiation therapy; TME: total mesorectal excision; TNM: tumor-node-metastasis; SPR: sphincter-preserving resection; APR: abdominoperineal resection; NE: not evaluated

Table 2. Recurrence after surgery

\begin{tabular}{lllc}
\hline & SPR $(\boldsymbol{n}=\mathbf{7 3})$ & APR $(\boldsymbol{n}=\mathbf{1 7})$ & $\boldsymbol{P}$ value \\
\hline Recurrence (\%) & $13(17.8)$ & $5(29.1)$ & 0.317 \\
Local & $5(6.8)$ & 0 & 0.248 \\
Distant & $8(11.0)$ & $5(29.1)$ & \\
Liver & 2 & 2 & \\
Lung & 5 & 2 & \\
Other & 1 & & \\
Median follow-up period, days (range) & $3958(2778-6583)$ & & \\
\hline
\end{tabular}

Data shown as $n$ (\%).SPR: sphincter-preserving resection; APR: abdominoperineal resection

differences in either were observed between the 2 groups $(P=0.751$ and $P=0.892$, respectively). The 5-year overall survival rate in the patients who underwent SPR was $100 \%$ for those with stage I disease, $86.5 \%$ for stage II disease, and $72.1 \%$ for stage III disease [Figure 2].

\section{Functional results}

During a median follow-up period of 1450 days (range 475-2544 days), 11 patients did not respond to the questionnaire. Surveys were stopped in 4 patients because of cancer recurrence. Two patients did not consent to an ileostomal closure. One patient required a permanent colostomy because of a perineal hernia after a pelvic-bone fracture. Ultimately, anal function was assessed in 55 of the 73 SPR patients (75.3\%): 18 conventional CAA patients, 22 partial ISR patients, and 15 massive ISR patients [Table 4]. The functional outcomes of the 3 groups are shown in Table 5.

A significant difference in the WI score $(P=0.005)$, LARS score $(P=0.002)$, and VAS score $(P=0.047)$ was observed between the 3 groups. 

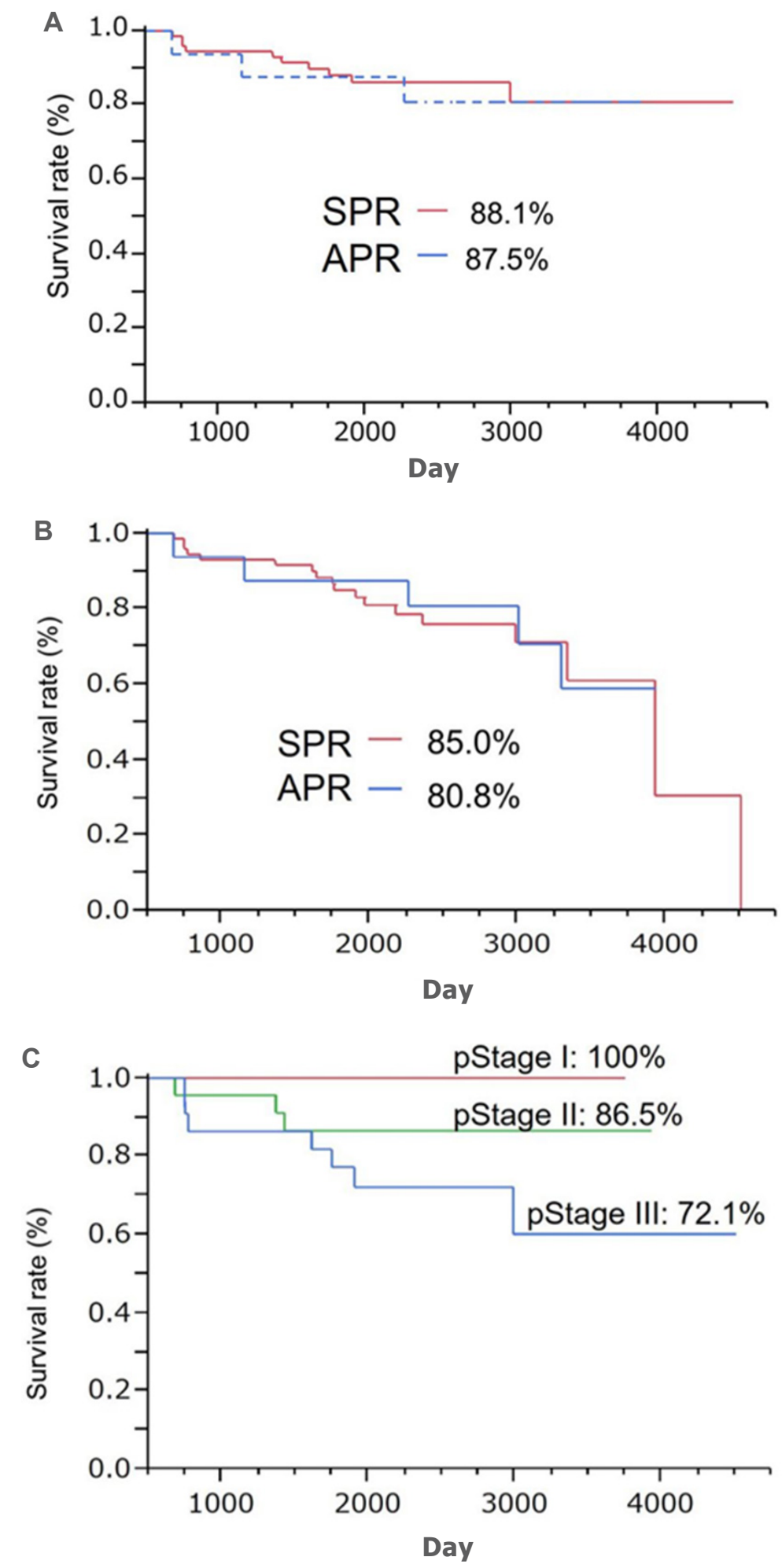

Figure 2. Kaplan-Meier survival rate in the sphincter-preserving resection and abdominoperineal resection groups. A: overall survival rate; $\mathrm{B}$ : disease-free survival rate; $\mathrm{C}$ : overall survival rate according to pathological stage in the sphincter-preserving resection group

\section{DISCUSSION}

Transanal approaches to pelvic dissection have attracted attention to improve oncologic and functional outcomes by providing better visualization and more accurate TME dissection. In 1984, Dr. Gerald Marks 
was the first surgeon to use a perineal approach to transanal dissection of the rectum for TME; his goal was to avoid leaving the patient with a permanent colostomy ${ }^{[20,21]}$. In April 2003, we implemented the TARD technique in laparoscopic SPR for LRC located $\leq 5 \mathrm{~cm}$ from the anal verge in order to achieve more accurate TME and to maintain the function of the IAS as much as possible after ISR ${ }^{[22]}$. A randomized trial showed that a transanal approach to TME was more effective than the conventional laparoscopic approach to TME in terms of negative circumferential resection margins and suggested that the perineal approach could be the new standard for laparoscopic SPR in Western patients with LRC ${ }^{[23]}$. However, in its long-term results, lower positivity of the circumferential resection margin did not translate into a decreased incidence of local recurrence ${ }^{[11]}$. Marks et al ${ }^{[12]}$ reported that the primary perineal approach reduces operative time and is associated with similar short- and long-term outcomes compared with the primary abdominal approach to laparoscopic ISR. On the other hand, two randomized controlled trials, the ALaCart ${ }^{[7]}$ and ACOSOG Z6051 ${ }^{[8]}$ trials, failed to show the noninferiority of laparoscopic surgery compared with open surgery for oncologic outcomes. Two multi-center, randomized, controlled trials, COLORIII ${ }^{[24]}$ and GRECCAR $11^{[25]}$, will provide more definitive results.

The feasibility and benefit of this approach for Asian patients, including Japanese patients, should be evaluated. To our knowledge, although there are many reports of SPR including ISR in Japanese patients ${ }^{[26-35]}$, ours is the first to describe the long-term oncologic and functional outcomes of SPR via the transanal approach in the Japanese population.

In the reports by Rouanet et al.$^{[36]}$, Denost et al.$^{[23]}$, Lacy et al.$^{[37]}$, Burke et al ${ }^{[38]}$, and Veltcamp Helbach et al. ${ }^{[39]}$, CRM positivity was $2.5 \%, 4 \%, 6.4 \%, 4 \%$, and $2.5 \%$, respectively. In this series, 17 patients $(18.9 \%$ ) required conversion to APR. In 14 of these, salvage APR was performed because tumor invasion into the levator ani muscle, prostate, or vagina was suspected during rectal dissection. As final histopathology revealed a negative CRM for each of these patients, TARD could be a useful approach for clinical T4b tumors. A good CRM of $93.1 \%$ was shown in the SPR group as well. Patients who underwent SPR had an overall survival rate of $88.1 \%$ and a disease-free survival rate of $84.9 \%$ after 5 years. This was not significantly different from patients who underwent APR. These results show that TARD has a potential benefit of being able to allow immediate conversion to APR as a salvage procedure when tumor invasion to the rectal dissection plane is suspected during SPR for advanced disease categorized as type II-III according to Rullier's classification. Local recurrence occurred in $6.8 \%$ of the SPR patients during a median follow-up period of 3958 days (range 2778-6583 days); these findings are similar to those of Rullier et al. ${ }^{[19]}$ who reported rates from $5 \%$ to $9 \%$ in 135 conventional CAA patients, 131 partial-ISR patients, and 55 total-ISR patients. For unclear reasons, local recurrence was only observed after ISR in this series. All patients with local recurrence were male with stage III disease, and 1 had received pre-CRT. Histologically, locally advanced disease was observed in most patients. No technical errors were reported in the operative records.

Postoperative anorectal function is a significant concern for patients undergoing SPR, including ISR. Although ISR has broadened the sphincter-preserving options for selected patients with LRC, impaired anorectal function after ISR remains a major problem. Many studies have found that patients undergoing SPR, including low anterior resection, conventional CAA, and ISR, are at risk for developing LARS (e.g., frequent bowel movements, urgency, and incontinence of flatus). A recent review found that, regardless of the use of preoperative irradiation, $0 \%$ to $5.9 \%$ of patients who undergo ISR require a colostomy for postprocedural anorectal dysfunction ${ }^{[40]}$. It is well known that the IAS plays an important role in fecal continence, and that extensive resection of the IAS during SPR is likely to impair anorectal function. Some risk factors associated with anorectal dysfunction after ISR include pre-CRT ${ }^{[41,42]}$, total resection of the IAS ${ }^{[43-45]}$, tumor level, height of the anastomosis ${ }^{[46]}$, and patient age ${ }^{[30]}$. In this series, pre-CRT was administered to 14 patients with locally advanced disease. Pre-CRT has been shown to negatively affect postsurgical function ${ }^{[47,48]}$.

Most researchers agree that anorectal dysfunction after ISR improves as time proceeds, but any remaining postoperative anorectal dysfunction after IAS resection is significant. 
Table 3. Details of local recurrence after surgery

\begin{tabular}{|c|c|c|c|c|c|c|c|c|c|c|c|c|}
\hline No. & Gender & $\begin{array}{c}\text { Age } \\
\text { (years) }\end{array}$ & cTNM & Pre-CRT & $\begin{array}{l}\text { Surgical } \\
\text { approach }\end{array}$ & $\begin{array}{l}\text { Tumor } \\
\text { size } \\
(\mathrm{mm})\end{array}$ & pTNM & CRM & $\begin{array}{c}\text { Lym- } \\
\text { phatic } \\
\text { vessel } \\
\text { invasion }\end{array}$ & $\begin{array}{l}\text { Recur- } \\
\text { rence site }\end{array}$ & Treatment & Status \\
\hline 1 & Male & 46 & T4N2MO & $\begin{array}{l}\text { P } \\
\text { (grade 2) }\end{array}$ & Open & 70 & T3NOMO & Complete & None & $\begin{array}{l}\text { Lt-lateral } \\
\text { lymph node }\end{array}$ & Chemo & Alive \\
\hline 2 & Male & 51 & T3N1M0 & N & Open & 85 & $\begin{array}{l}\text { T4bN2bMO } \\
\text { (prostate) }\end{array}$ & Incomplete & Moderate & $\begin{array}{l}\text { Lt-lateral } \\
\text { lymph node }\end{array}$ & RT + Chemo & Dead \\
\hline 3 & Male & 63 & T3N1M0 & N & Open & 60 & T3N1bNO & Complete & Moderate & $\begin{array}{l}\text { Rt-lateral } \\
\text { lymph node }\end{array}$ & RT + Chemo & Dead \\
\hline 4 & Male & 63 & T3N1MO & $N$ & Open & 75 & T3N1bNO & Complete & Slight & Pelvis & Chemo & Dead \\
\hline 5 & Male & 59 & T3N1M0 & $N$ & Laparoscopic & 20 & T3N2aMo & Complete & Slight & Prostate & $\begin{array}{l}\text { RT + Chemo } \\
\text { TPE }\end{array}$ & Alive \\
\hline
\end{tabular}

Pre-CRT: preoperative chemoradiation therapy; P: positive; N: negative; pTNM: pathologic tumor-node-metastasis; Chemo: chemotherapy; CRM: circumferential resection margins; RT: radiation therapy; TPE: total pelvic exenteration; Lt: left; Rt: right

Table 4. Characteristics of the CAA, partial ISR and massive ISR patients

\begin{tabular}{|c|c|c|c|}
\hline & Conventional CAA $(n=18)$ & Partial ISR $(n=22)$ & Massive ISR $(n=15)$ \\
\hline \multicolumn{4}{|l|}{ Gender } \\
\hline Male & 13 & 17 & 7 \\
\hline Female & 5 & 5 & 8 \\
\hline Age, years (range) & $59(46-79)$ & $62(34-77)$ & $56(33-70)$ \\
\hline $\mathrm{BMI}, \mathrm{kg} / \mathrm{m}^{2}$ (range) & $22.1(16.5-32.9)$ & $24.7(16.9-31.2)$ & $20.4(18.3-26.5)$ \\
\hline Pre-CRT (\%) & $3(16.7)$ & $5(22.7)$ & $1(6.7)$ \\
\hline \multicolumn{4}{|l|}{ Reconstruction } \\
\hline Pouch & 0 & 3 & 3 \\
\hline Straight & 18 & 19 & 12 \\
\hline Complication related to anastomosis (\%) & 0 & $4(18.2)$ & $2(13.3)$ \\
\hline Prolapse & 0 & 1 & 1 \\
\hline Anastomotic structure & 0 & 3 & 1 \\
\hline
\end{tabular}

Data shown as median (range) or $n$ (\%). BMI: body mass index; CAA: coloanal anastomosis; Pre-CRT: preoperative chemoradiation therapy; ISR: intersphincteric resection

Table 5. Long-term function after sphincter-preserving resection

\begin{tabular}{lllll}
\hline & $\begin{array}{c}\text { Conventional CAA } \\
(\boldsymbol{n}=\mathbf{1 8})\end{array}$ & $\begin{array}{c}\text { Partial ISR } \\
(\boldsymbol{n}=\mathbf{2 2})\end{array}$ & $\begin{array}{c}\text { Massive ISR } \\
(\boldsymbol{n}=\mathbf{1 5})\end{array}$ & $\begin{array}{c}\boldsymbol{P} \text { value } \\
\text { Follow-up period, days (range) }\end{array}$ \\
Daily bowel movements & $1096(475-2508)$ & $1467(748-2537)$ & $1814(728-2544)$ & - \\
Urgency (\%) & 0.8 & 2.6 & 2.2 & $\mathrm{NS}$ \\
Fecal incontinence & $1(5.6)$ & $6(27.3)$ & $4(26.7)$ & $\mathrm{NS}$ \\
WI score & 0 & $2(9.1)$ & $1(6.7)$ & $\mathrm{NS}$ \\
LARS score & $5(0-14)$ & $10(0-20)$ & $10(5-20)$ & 0.005 \\
VAS score & $28 \pm 6$ & $33 \pm 9$ & $36 \pm 3$ & 0.002 \\
Complication related to coloanal anastomosis (\%) & $7.8 \pm 1.5$ & $6.4 \pm 2.9$ & $6.6 \pm 1.5$ & 0.047 \\
Prolapse & 0 & $4(18.2)$ & $2(13.3)$ & $\mathrm{NS}$ \\
Anastomotic stricture & 0 & 1 & 1 & \\
\hline
\end{tabular}

Data shown as median (range) or $n$ (\%). CAA: coloanal anastomosis; ISR: intersphincteric resection; WI: Wexner incontinence; LARS: low anterior resection syndrome; VAS: visual analogue scale

In this series, we were able to preserve the IAS completely in 18 patients $(28.8 \%)$ using the TARD technique; consequently, this might minimize postoperative anorectal dysfunction in these patients. These results show again the significance of preserving the IAS for anorectal function after surgery ${ }^{[4]}$.

This study showed the clinical feasibility of TARD under direct vision in SPR for LRC. TARD could represent a step toward a minimally invasive, natural orifice, transluminal endoscopic surgery. However, 
this study is limited by its single-institution nature, its lack of a control group, and its small sample size. In addition, most TARD procedures were performed by a single surgeon (KF); therefore, the potential for selection bias is significant. Our data must be interpreted in the context of these potential biases. Recently, TaTME utilizing laparoscopic instruments has been developed as a novel alternative to intersphincteric resection that provides solutions to many of the limitations of TARD, as it is performed under direct visualization ${ }^{[50]}$. We recommend that further studies should be performed to confirm that transanal surgery is feasible and of benefit for Japanese and all Asian patients.

Using TARD under direct vision during laparoscopic and open SPR for LRC has no negative effects on oncologic outcomes. However, resection of the IAS should be avoided, where possible, to minimize anorectal dysfunction after ISR. This approach is feasible for Japanese patients with LRC. Further studies that compare TaTME utilizing laparoscopic instruments with conventional transabdominal TME are required to fully understand the risks and benefits of this approach for the Japanese and greater Asian populations.

\section{DECLARATIONS}

\section{Authors' contributions}

Conception and design of the study: Teramoto $\mathrm{T}$

Collection and assembly of data: Shiokawa H, Ushigome M, Kaneko T, Kagami S, Koda T

Analysis and interpretation of data: Koike J

\section{Availability of data and materials}

The data is presented and kept by the author and is available for scrutiny.

\section{Financial support and sponsorship}

None.

\section{Conflicts of interest}

The authors declare that there are no conflicts of interest.

\section{Ethical approval and consent to participate}

The Ethics Committee of Toho University Omori Medical Center (No. 17-41) approved the study, which was conducted in accordance with the Helsinki Declaration and the standards of the Ethics Committee. Written informed consent was obtained from all patients in this study.

\section{Consent for publication}

Not applicable.

\section{Copyright}

(c) The Author(s) 2018.

\section{REFERENCES}

1. Enker WE, Thaler HT, Cranor ML, Polyak T. Total mesorectal excision in the operative treatment of carcinoma of the rectum. J Am Coll Surg 1995;181:335-46.

2. Heald RJ, Husband EM, Ryall RD. The mesorectum in rectal cancer surgery--the clue to pelvic recurrence? Br J Surg 1982;69:613-6.

3. Quirke P, Dixon MF. The prediction of local recurrence in rectal adenocarcinoma by histopathological examination. Int J Colorectal Dis 1988;3:127-31.

4. Adam IJ, Mohamdee MO, Martin IG, Scott N, Finan PJ, Johnston D, Dixon MF, Quirke P. Role of circumferential margin involvement in the local recurrence of rectal cancer. Lancet 1994;344:707-11.

5. Targarona EM, Balague C, Pernas JC, Martinez C, Berindoague R, Gich I, Trias Ml. Can we predict immediate outcome after laparoscopic rectal surgery? Multivariate analysis of clinical, anatomic, and pathologic features after 3-dimensional reconstruction of the pelvic anatomy. Ann Surg 2008;247:642-9.

6. Akiyoshi T, Kuroyanagi H, Oya M, Konishi T, Fukuda M, Fujimoto Y, Ueno M, Miyata S, Yamaguchi T. Factors affecting the difficulty 
of laparoscopic total mesorectal excision with double stapling technique anastomosis for low rectal cancer. Surgery 2009;146:483-9.

7. Stevenson AR, Solomon MJ, Lumley JW, Hewett P, Clouston AD, Gebski VJ, Davies L, Wilson K, Hague W, Simes J; ALaCaRT Investigators. Effect of laparoscopic-assisted resection vs open resection on pathological outcomes in rectal cancer: the ALaCaRT randomized clinical trial. JAMA 2015;314:1356-63.

8. Fleshman J, Branda M, Sargent DJ, Boller AM, George V, Abbas M, Peters WR Jr, Maun D, Chang G, Herline A, Fichera A, Mutch M, Wexner S, Whiteford M, Marks J, Birnbaum E, Margolin D, Larson D, Marcello P, Posner M, Read T, Monson J, Wren SM, Pisters PW, Nelson H. Effect of laparoscopic-assisted resection vs open resection of stage II or III rectal cancer on pathologic outcomes: the ACOSOG Z6051 randomized clinical trial. JAMA 2015;314:1346-55.

9. Schiessel R, Karner-Hanusch J, Herbst F, Teleky B, Wunderlich M. Intersphincteric resection for low rectal tumours. Br J Surg 1994;81:1376-8.

10. Park JS, Choi GS, Jun SH, Hasegawa S, Sakai Y. Laparoscopic versus open intersphincteric resection and coloanal anastomosis for low rectal cancer: intermediate-term oncologic outcomes. Ann Surg 2011;254:941-6.

11. Denost Q, Loughlin P, Chevalier R, Celerier B, Didailler R, Rullier E. Transanal versus abdominal low rectal dissection for rectal cancer: long-term results of the Bordeaux' randomized trial. Surg Endosc 2018;32:1486-94.

12. Marks JH, Montenegro GA, Salem JF, Shields MV, Marks GJ. Transanal TATA/TME: a case-matched study of taTME versus laparoscopic TME surgery for rectal cancer. Tech Coloproctol 2016;20:467-73.

13. Xu W, Xu Z, Cheng H, Ying J, Cheng F, Xu W, Cao J, Luo J. Comparison of short-term clinical outcomes between transanal and laparoscopic total mesorectal excision for the treatment of mid and low rectal cancer: a meta-analysis. Eur J Surg Oncol 2016;42:1841-50.

14. Yoshiike N, Seino F, Tajima S, Arai Y, Kawano M, Furuhata T, Inoue S. Twenty-year changes in the prevalence of overweight in Japanese adults: the National Nutrition Survey 1976-95. Obes Rev 2002;3:183-90.

15. Matsushita Y, Takahashi Y, Mizoue T, Inoue M, Noda M, Tsugane S; JPHC Study Group. Overweight and obesity trends among Japanese adults: a 10-year follow-up of the JPHC Study. Int J Obes (Lond) 2008;32:1861-7.

16. Funahashi K, Koike J, Teramoto T, Saito N, Shiokawa H, Kurihara A, Kaneko T, Shirasaka K, Kaneko H. Transanal rectal dissection: a procedure to assist achievement of laparoscopic total mesorectal excision for bulky tumor in the narrow pelvis. Am J Surg 2009;197:e46-50.

17. Kneist W, Rink AD, Kauff DW, Konerding MA, Lang H. Topography of the extrinsic internal anal sphincter nerve supply during laparoscopic-assisted TAMIS TME: five key zones of risk from the surgeons' view. Int J Colorectal Dis 2015;30:71-8.

18. Emmertsen KJ, Laurberg S. Low anterior resection syndrome score: development and validation of a symptom-based scoring system for bowel dysfunction after low anterior resection for rectal cancer. Ann Surg 2012;255:922-8.

19. Rullier E, Denost Q, Vendrely V, Rullier A, Laurent C. Low rectal cancer: classification and standardization of surgery. Dis Colon Rectum 2013;56:560-7.

20. Marks JH, Frenkel JL, D'Andrea AP, Greenleaf CE. Maximizing rectal cancer results: TEM and TATA techniques to expand sphincter preservation. Surg Oncol Clin N Am 2011;20:501-20.

21. Bannon JP, Marks GJ, Mohiuddin M, Rakinic J, Jian NZ, Nagle D. Radical and local excisional methods of sphincter-sparing surgery after high-dose radiation for cancer of the distal $3 \mathrm{~cm}$ of the rectum. Ann Surg Oncol 1995;2:221-7.

22. Funahashi K, Shiokawa H, Teramoto T, Koike J, Kaneko H. Clinical outcome of laparoscopic intersphincteric resection combined with transanal rectal dissection for $\mathrm{t} 3$ low rectal cancer in patients with a narrow pelvis. Int J Surg Oncol 2011;2011:901574.

23. Denost Q, Adam JP, Rullier A, Buscail E, Laurent C, Rullier E. Perineal transanal approach: a new standard for laparoscopic sphinctersaving resection in low rectal cancer, a randomized trial. Ann Surg 2014;260:993-9.

24. Deijen CL, Velthuis S, Tsai A, Mavroveli S, de Lange-de Klerk ES, Sietses C, Tuynman JB, Lacy AM, Hanna GB, Bonjer HJ. COLOR III: a multicentre randomised clinical trial comparing transanal TME versus laparoscopic TME for mid and low rectal cancer. Surg Endosc 2016;30:3210-5.

25. Institut Paoli-Calmettes. Evaluate efficacy, morbidity and functional outcome of endoscopic trananal proctectomy vs standard transabdominal laparoscopic proctectomy for rectal cancer (ETAP). ClinicalTrials.gov Identifier: NCT02584985.

26. Saito N, Ito M, Kobayashi A, Nishizawa Y, Kojima M, Nishizawa Y, Sugito M. Long-term outcomes after intersphincteric resection for low-lying rectal cancer. Ann Surg Oncol 2014;21:3608-15.

27. Koyama M, Murata A, Sakamoto Y, Morohashi H, Takahashi S, Yoshida E, Hakamada K. Long-term clinical and functional results of intersphincteric resection for lower rectal cancer. Ann Surg Oncol 2014;21 Suppl 3:S422-8.

28. Akagi Y, Shirouzu K, Ogata Y, Kinugasa T. Oncologic outcomes of intersphincteric resection without preoperative chemoradiotherapy for very low rectal cancer. Surg Oncol 2013;22:144-9.

29. Fujii S, Yamamoto S, Ito M, Yamaguchi S, Sakamoto K, Kinugasa Y, Kokuba Y, Okuda J, Yoshimura K, Watanabe M. Short-term outcomes of laparoscopic intersphincteric resection from a phase II trial to evaluate laparoscopic surgery for stage 0/I rectal cancer: Japan Society of Laparoscopic Colorectal Surgery Lap RC. Surg Endosc 2012;26:3067-76.

30. Yamamoto S, Fujita S, Akasu T, Inada R, Takawa M, Moriya Y. Short-term outcomes of laparoscopic intersphincteric resection for lower rectal cancer and comparison with open approach. Dig Surg 2011;28:404-9.

31. Fujimoto Y, Akiyoshi T, Kuroyanagi H, Konishi T, Ueno M, Oya M, Yamaguchi T. Safety and feasibility of laparoscopic intersphincteric resection for very low rectal cancer. J Gastrointest Surg 2010;14:645-50.

32. Sakakura C, Nishio M, Miyagawa K, Miyashita A, Nagata H, Kin S, Fukuda K, Nakase Y, Hagiwara A, Nakanishi M, Yamazaki J, Yoshikawa S, Okamoto K, Kokuba Y, Otsuji E. Laparoscope-assisted superlow anterior resection combined with inter sphincteric rectal dissection for very low advanced rectal cancers combined with preoperative chemotherapy. Hepatogastroenterology 2009;56:692-5.

33. Yamada K, Ogata S, Saiki Y, Fukunaga M, Tsuji Y, Takano M. Long-term results of intersphincteric resection for low rectal cancer. Dis Colon Rectum 2009;52:1065-71.

34. Saito N, Sugito M, Ito M, Kobayashi A, Nishizawa Y, Yoneyama Y, Nishizawa Y, Minagawa N. Oncologic outcome of intersphincteric resection for very low rectal cancer. World J Surg 2009;33:1750-6. 
35. Saito N, Moriya Y, Shirouzu K, Maeda K, Mochizuki H, Koda K, Hirai T, Sugito M, Ito M, Kobayashi A. Intersphincteric resection in patients with very low rectal cancer: a review of the Japanese experience. Dis Colon Rectum 2006;49:S13-22.

36. Rouanet P, Mourregot A, Azar CC, Carrere S, Gutowski M, Quenet F, Saint-Aubert B, Colombo PE. Transanal endoscopic proctectomy: an innovative procedure for difficult resection of rectal tumors in men with narrow pelvis. Dis Colon Rectum 2013;56:408-15.

37. Lacy AM, Tasende MM, Delgado S, Fernandez-Hevia M, Jimenez M, De Lacy B, Castells A, Bravo R, Wexner SD, Heald RJ. Transanal total mesorectal excision for rectal cancer: outcomes after 140 patients. J Am Coll Surg 2015;221:415-23.

38. Burke JP, Martin-Perez B, Khan A, Nassif G, de Beche-Adams T, Larach SW, Albert MR, Atallah S. Transanal total mesorectal excision for rectal cancer: early outcomes in 50 consecutive patients. Colorectal Dis 2016;18:570-7.

39. Veltcamp Helbach M, Deijen CL, Velthuis S, Bonjer HJ, Tuynman JB, Sietses C. Transanal total mesorectal excision for rectal carcinoma: short-term outcomes and experience after 80 cases. Surg Endosc 2016;30:464-70.

40. Akagi Y, Kinugasa T, Shirouzu K. Intersphincteric resection for very low rectal cancer: a systematic review. Surg Today 2013;43:83847.

41. Ammann K, Kirchmayr W, Klaus A, Mühlmann G, Kafka R, Oberwalder M, De Vries A, Ofner D, Weiss H. Impact of neoadjuvant chemoradiation on anal sphincter function in patients with carcinoma of the midrectum and low rectum. Arch Surg 2003;138:257-61.

42. Ito M, Saito N, Sugito M, Kobayashi A, Nishizawa Y, Tsunoda Y. Analysis of clinical factors associated with anal function after intersphincteric resection for very low rectal cancer. Dis Colon Rectum 2009;52:64-70.

43. Kuijpers JH. Fecal continence after subtotal to total excision of the rectum. Neth J Surg 1983;35:73-7.

44. Hallböök O, Påhlman L, Krog M, Wexner SD, Sjödahl R. Randomized comparison of straight and colonic J pouch anastomosis after low anterior resection. Ann Surg 1996;224:58-65.

45. Yamada K, Ogata S, Saiki Y, Fukunaga M, Tsuji Y, Takano M. Functional results of intersphincteric resection for low rectal cancer. Br J Surg 2007;94:1272-7.

46. Denost Q, Laurent C, Capdepont M, Zerbib F, Rullier E. Risk factors for fecal incontinence after intersphincteric resection for rectal cancer. Dis Colon Rectum 2011;54:963-8.

47. Yoo JH, Hasegawa H, Ishii Y, Nishibori H, Watanabe M, Kitajima M. Long-term outcome of per anum intersphincteric rectal dissection with direct coloanal anastomosis for lower rectal cancer. Colorectal Dis 2005;7:434-40.

48. Fucini C, Elbetti C, Petrolo A, Casella D. Excision of the levator muscles with external sphincter preservation in the treatment of selected low T4 rectal cancers. Dis Colon Rectum 2002;45:1697-705.

49. Shiokawa H, Funahashi K, Kaneko H, Teramoto T. Long-term assessment of anorectal function after extensive resection of the internal anal sphincter for treatment of low-lying rectal cancer near the anus. J Anus Rectum Colon 2017;1:29-34.

50. Maykel JA. Laparoscopic transanal total mesorectal excision (taTME) for rectal cancer. J Gastrointest Surg 2015;19:1880-8. 